\title{
The Effect of Suspended Sediment and Color on Ultraviolet Spectrophotometric Nitrate Sensors
}

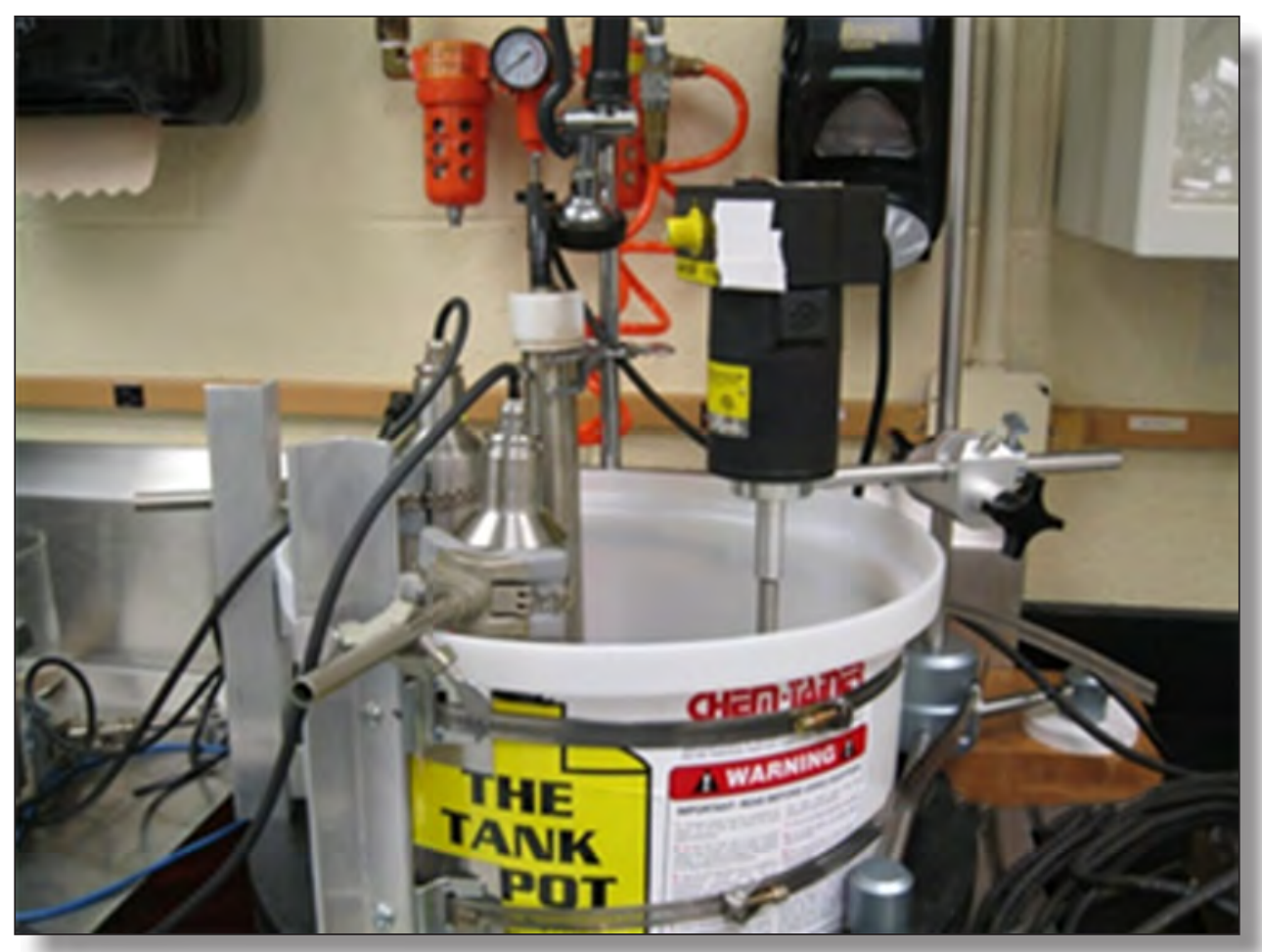

Open-File Report 2016-1014 
Cover photograph. Hach NITRATAX (2-mm), Hach NITRAX (5-mm), and the S::CAN Spectro::Iyser (5-mm) nitrate sensors in the tank apparatus. 


\section{The Effect of Suspended Sediment and Color on Ultraviolet Spectrophotometric Nitrate Sensors}

By Teri T. Snazelle

Open-File Report 2016-1014 


\title{
U.S. Department of the Interior SALLY JEWELL, Secretary
}

\section{U.S. Geological Survey Suzette M. Kimball, Director}

\author{
U.S. Geological Survey, Reston, Virginia: 2016
}

For more information on the USGS - the Federal source for science about the Earth, its natural and living resources, natural hazards, and the environment—visit http://www.usgs.gov or call 1-888-ASK-USGS.

For an overview of USGS information products, including maps, imagery, and publications, visit http://www.usgs.gov/pubprod/.

Any use of trade, firm, or product names is for descriptive purposes only and does not imply endorsement by the U.S. Government.

Although this information product, for the most part, is in the public domain, it also may contain copyrighted materials as noted in the text. Permission to reproduce copyrighted items must be secured from the copyright owner.

Suggested citation:

Snazelle, T.T., 2016, The effect of suspended sediment and color on ultraviolet spectrophotometric nitrate sensors: U.S. Geological Survey Open-File Report, 2016-1014, 10 p., http://dx.doi.org/10.3133/ofr20161014.

ISSN 2331-1258 (online) 


\section{Contents}

Abstract
Introduction
Description of Spectrophotometric Nitrate Sensors
Test Procedures
Turbidity/Total Suspended-Sediment Effect on Accuracy
Test Results Dissolved Organic Matter Effect on Accuracy
Turbidity and Total Suspended-Sediment Effect on Accuracy
Colored Dissolved Organic Matter Effect on Accuracy
References Cited.

\section{Figures}

1. Photographs of nitrate sensors: Hach NITRATAX $5 \mathrm{~mm}$; Hach NITRATAX

$2 \mathrm{~mm}$ S::CAN Spectro::Iyser; and Satlantic SUNA V2 .................................................

2. Schematic Illustration of a spectrophotometer..............................................................

3. Photograph taken during the first round of suspended sediment testing showing the Hach NITRATAX, Hach NITRATAX, and the S::CAN Spectro::Iyser nitrate sensors in the tank apparatus .

4. Photograph taken during the second round of suspended-sediment testing showing the Hach NITRATAX, Hach NITRATAX, S::CAN Spectro::Iyser, and the SUNA V2 nitrate sensors in the tank apparatus.

5. Photograph of the National Institute of Standards and Technology standard reference material 1646a-estuarine sediment...

6. Photograph of the prefiltered brewed tea used in the test for colored dissolved organic matter.

7. Graphs showing difference between the initial nitrate measurement and subsequent nitrate measurements of the 5 milligrams-nitrogen-per-liter solution by the Hach NITRATAX, Hach NITRATAX, S::CAN, and SUNA V2 nitrate sensors in suspended-sediment concentration values from $0-4,500 \mathrm{mg} / \mathrm{L}$

8. Photographs showing the initial clear matrix spike of the turbidity/total suspended sediment test and the ending matrix spike of the turbidity/tss test containing the addition of 4,500 milligrams per liter of National Institute of Standards and Technology standard reference material 1646a-estuarine sediment.

9. Photographs showing the observed color change as the estimated total organic carbon increases

10. Graphs showing percent increase in measured nitrate concentration by the Hach NITRATAX, Hach NITRATAX, S::CAN, and SUNA V2 nitrate sensors against increasing estimated total organic carbon. Turbidity is plotted as the red squares in formazin nephelometric units. 


\section{Tables}

1. Nitrate sensor features and manufacturer specifications

Note: Tables 2, 3, and 4 are available for download in Excel format at http://dx.doi.org/10.3133/ofr20161014.

2. Nitrate measurements by three ultraviolet nitrate sensors in water with a 5-mgNL concentration and with varying concentrations of National Institute of Standards and Technology standard reference material 1646a sediment (first test).

3. Nitrate measurements by four ultraviolet nitrate sensors in water with a 5-mgNL concentration and with varying concentrations of National Institute of Standards and Technology standard reference material 1646a sediment (second test).

4. Nitrate measurements by four ultraviolet nitrate sensors in water with a 5-mg$\mathrm{NL}$ concentration and with varying concentrations of filtered tea.

\section{Conversion Factors}

stro habreneace

\begin{tabular}{lll}
\hline \multicolumn{1}{c}{ Multiply } & \multicolumn{1}{c}{ By } & \multicolumn{1}{c}{ To obtain } \\
\hline centimeter $(\mathrm{cm})$ & Length & \\
millimeter $(\mathrm{mm})$ & 0.3937 & inch (in.) \\
micrometer $(\mu \mathrm{m})$ & 0.03937 & inch (in.) \\
nanometer $(\mathrm{nm})$ & 0.00003937 & inch (in.) \\
& 0.00000003937 & inch (in.) \\
\hline liter $(\mathrm{L})$ & Volume & \\
liter $(\mathrm{L})$ & 33.82 & ounce, fluid (fl. oz.) \\
\hline
\end{tabular}

Temperature in degrees Celsius $\left({ }^{\circ} \mathrm{C}\right)$ may be converted to degrees Fahrenheit $\left({ }^{\circ} \mathrm{F}\right)$ as follows:

${ }^{\circ} \mathrm{F}=\left(1.8 x^{\circ} \mathrm{C}\right)+32$

Temperature in degrees Fahrenheit $\left({ }^{\circ} \mathrm{F}\right)$ may be converted to degrees Celsius $\left({ }^{\circ} \mathrm{C}\right)$ as follows:

${ }^{\circ} \mathrm{C}=\left({ }^{\circ} \mathrm{F}-32\right) / 1.8$ 


\section{Abbreviations}

$\begin{array}{ll}\text { CDOM } & \text { colored dissolved organic matter } \\ \text { EDOC } & \text { estimated dissolved organic carbon } \\ \text { ETOC } & \text { estimated total organic carbon } \\ \text { FNU } & \text { formazin nephelometric units } \\ \text { HIF } & \text { Hydrologic Instrumentation Facility (USGS) } \\ \text { NIST } & \text { National Institute of Standards and Technology } \\ \text { SSC } & \text { suspended-sediment concentration } \\ \text { TSS } & \text { total suspended sediment } \\ \text { USGS } & \text { U.S. Geological Survey } \\ \text { UV } & \text { ultraviolet }\end{array}$





\title{
The Effect of Suspended Sediment and Color on Ultraviolet Spectrophotometric Nitrate Sensors
}

\author{
By Teri T. Snazelle
}

\begin{abstract}
Four commercially available ultraviolet nitrate spectrophotometric sensors were evaluated by the U.S. Geological Survey Hydrologic Instrumentation Facility (HIF) to determine the effects of suspended sediment concentration (SSC) and colored dissolved organic matter (CDOM) on sensor accuracy. The evaluated sensors were: the Hach NITRATAX plus sc (5-millimeters (mm) path length), Hach NITRATAX plus sc (2 mm), S::CAN Spectro::lyser (5 mm), and the Satlantic SUNA V2 (5 mm). A National Institute of Standards and Technology-traceable nitrate-free sediment standard was purchased and used to create the turbid environment, and an easily made filtered tea solution was used for the CDOM test. All four sensors performed well in the test that evaluated the effect of suspended sediment on accuracy. The Hach $5 \mathrm{~mm}$, Hach $2 \mathrm{~mm}$, and the SUNA V2 met their respective manufacturer accuracy specifications up to concentrations of 4,500 milligrams per liter (mg/L) SSC. The S::CAN failed to meet its accuracy specifications when the SSC concentrations exceeded 4,000 mg/L. Test results from the effect of CDOM on accuracy indicated a significant skewing of data from all four sensors and showed an artificial elevation of measured nitrate to varying amounts. Of the four sensors tested, the Satlantic SUNA V2's accuracy was affected the least in the CDOM test. The nitrate concentration measured by the SUNA V2 was approximately 24 percent higher than the actual concentration when estimated total organic carbon values exceeded $44 \mathrm{mg} / \mathrm{L}$. Measured nitrate concentration falsely increased 49 percent when measured by the Hach $5 \mathrm{~mm}$, and 75 percent when measured by the Hach $2 \mathrm{~mm}$. The S::CAN's reported nitrate concentration increased 96 percent. Path length plays an important role in the sensor's ability to compensate measurements for matrix interferences, but does not solely determine how well a sensor can handle all interferences. The sensor's proprietary algorithms also play a key role in matrix interference compensation. The sensors' ability to compensate for CDOM varied significantly during the tests, even among the three with 5-mm path lengths. Results of this evaluation suggest that the proprietary algorithms of the nitrate analyzers are more effective compensating for suspended sediment, and less effective compensating for CDOM (color) when sensor path length remains constant.
\end{abstract}

\section{Introduction}

The U.S. Geological Survey (USGS) Hydrologic Instrumentation Facility (HIF) evaluates the performance of instruments and equipment that are used to directly measure hydrologic data. Instrument and equipment evaluations are done primarily to determine if particular devices would be suitable for use by USGS personnel for hydrologic data collection. Evaluation reports document the results at the time of testing, and may or may not represent future conditions resulting from updates and improvements to the device. Suspended sediment and colored dissolved organic matter (CDOM) are some of the most problematic matrix interferences to optical sensors. They are particularly troublesome with spectrophotometric sensors due to the skewing of direct wavelength absorption measurement (a) by scattering of the light (turbidity) or (b) by the absorption of visible and ultraviolet (UV) light of CDOM, which biases the measured concentration high (Blough and Del Vecchio, 2002). This report describes a laboratory evaluation on the effect of these interferences on the accuracy of UV spectrophotometric nitrate sensors.

Four nitrate sensors were tested during this two-phase evaluation: Hach NITRATAX plus sc 5-millimeter (mm) path length, Hach NITRATAX plus sc 2-mm path length, S::CAN Spectro::lyser 5-mm path length, and Satlantic SUNA V2 5-mm path length (fig. 1). In the first phase, sensor accuracy was tested against the effect of highly turbid water with heavy suspendedsediment concentration (SSC). The second phase evaluated the effect of CDOM on sensor accuracy. 


\section{Description of Spectrophotometric Nitrate Sensors}

Recent advances in technology have led to the development of self-contained, submersible sensors that can deliver continuous monitoring for nitrate-plus-nitrite concentration. In contrast to some previous models that relied on reagents, cadmium reduction, and visible spectrophotometry, these sensors provide a chemical-free and cost-effective alternative through the use of UV spectrophotometry (American Public Health Association, 1989). The optical system of a spectrophotometer comprises three main parts (fig. 2):

- A light source (lamp) - usually deuterium or xenon.

- A sample optical path length - usually 2 to 100 millimeters (mm).

- A photoelectric detector.

The matrix to be tested (normally water) flows into the instrument's measurement window and is illuminated with a beam of light. This light beam is separated into various wavelengths in the UV-visible (UV-Vis) spectrum (190-740 nanometers (nm)) by means of either a diffraction grating or monochromatic optical filter and is subsequently projected on a photoelectric detector. The energy measured by the spectrophotometer for each wavelength produces a raw "spectral fingerprint" or absorption spectrum of the water sample. The raw absorption spectrum is processed by proprietary-signal processing algorithms into a filtered absorption spectrum. The nitrate concentration is calculated from the filtered absorption spectrum using the Beer-Lambert Law, or Beer's Law.

The Hach NITRATAX ( $2 \mathrm{~mm}$ and $5 \mathrm{~mm}$ ) uses a primary light-beam wavelength of $210 \mathrm{~nm}$ to measure nitrate plus nitrite, and a secondary reference light-beam wavelength of $350 \mathrm{~nm}$ to correct for matrix interferences. The SUNA V2 measures nitrate plus nitrite using a $217-240$-nm wavelength light beam. The spectrum is processed into approximately 35 divisions or "channels" from which the absorbance is calculated and the contributing absorbing constituents are decomposed using the method developed at the Monterey Bay Aquarium Research Institute (MBARI) (Johnson and Coletti, 2002). The S::CAN
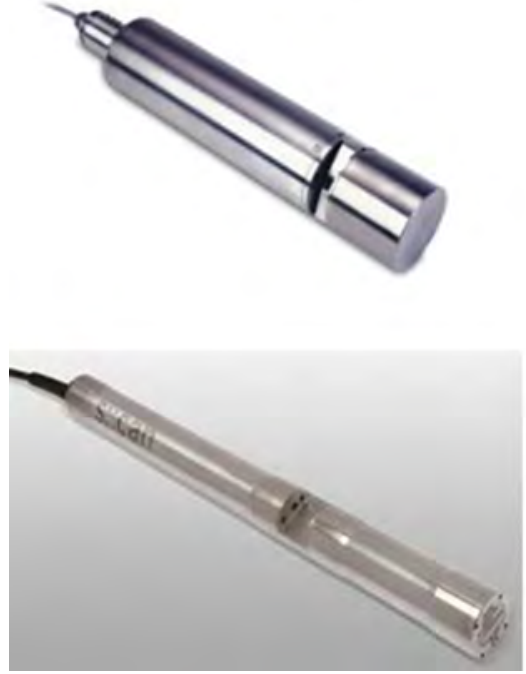
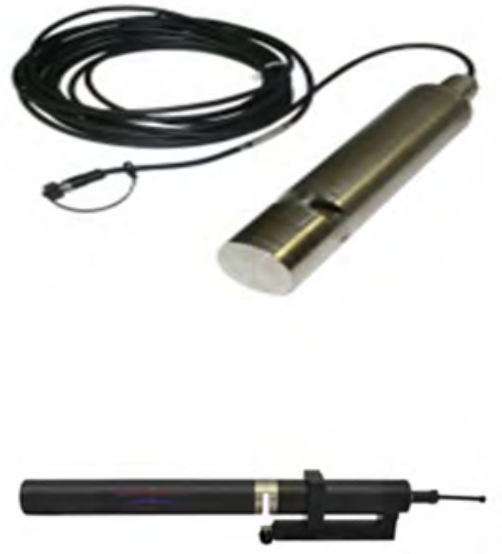

Figure 1. Photographs of nitrate sensors: Hach NITRATAX $5 \mathrm{~mm}$ (top left); Hach NITRATAX $2 \mathrm{~mm}$ (top right); S::CAN Spectro::lyser (bottom left); and Satlantic SUNA V2 (bottom right).

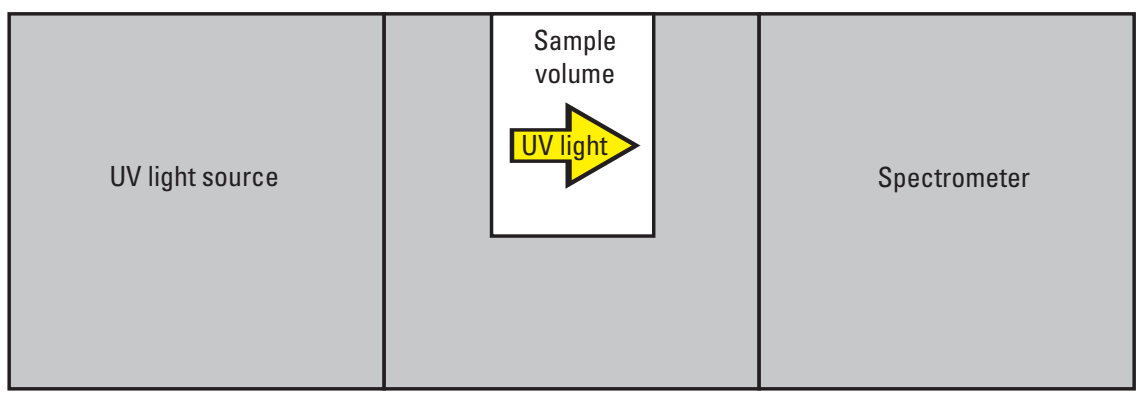

Figure 2. Schematic Illustration of a spectrophotometer. 
Spectro::lyser UV-Vis measures the complete absorbance spectrum between 190 and $720 \mathrm{~nm}$. This spectrum is resolved into a 256-wavelength "fingerprint" that makes it possible to monitor multiple parameters simultaneously and compensate for uncharacterized substances that interfere with these parameters. The analyzers are available commercially with prices varying from $\$ 15,000$ to $\$ 25,000$, depending on optional accessories. The instruments differ in their light sources, optical configuration, measurement path length, communication protocols, antifouling measures, and algorithms used to compute nitrate from the UV absorbance of the water sample.

Natural waters contain a mixture of substances that can create challenges for optical sensors. These substances can reduce the amount of transmitted light (turbidity) or absorb light in the same UV spectral range as nitrate and cause a bias in the calculated concentration. Two factors that influence how well a sensor can compensate for these interfering substances are the path length and data-processing algorithms. In general, a shorter path length will generally expand the nitrate detection range and minimize adverse effects from matrix interferences, such as turbidity, but will limit the sensitivity of the sensor at low concentrations. A longer path length will provide greater sensitivity at low concentrations, but will reduce the detection range and increase the effect of interferences. The effect of CDOM on UV absorption is not as readily managed. The S::CAN Spectro::lyser UV-Vis measures and reports turbidity, estimated total organic carbon (ETOC), and estimated dissolved organic carbon (EDOC), independently. To estimate total organic carbon and dissolved organic carbon, the Spectro::lyser scans wavelengths from $200-735 \mathrm{~nm}$ and, using a proprietary algorithm, translates this information into an estimated value. The Spectro::lyser calculates the amount of interference and subtracts it from the reported nitrate measurement. The user manuals for the Hach NITRATAX (Danaher Business System [2012a]) and SUNA V2 (Danaher Business System [2012b]) state that CDOM (color) in natural waters does not affect absorption, and, therefore, does not interfere with nitrate measurement (Danaher Business System, 2014 [SUNA]; 2015 [Hach]).

Table 1 gives a summary of each sensor's available features, technical specifications, path lengths, and firmware of the sensors at the time of testing. Additional information on the analyzers can be found in USGS Open-File Report 2015-1065, "Results from laboratory and field testing of nitrate measuring spectrophotometers" (Snazelle, 2015) and in USGS Techniques and Methods 1-D5, "Optical techniques for the determination of nitrate in environmental waters: Guidelines for instrument selection, operation, deployment, maintenance, quality assurance, and data reporting" (Pellerin and others, 2013) .

Table 1. Nitrate sensor features and manufacturer specifications.

[UV, ultraviolet; nm, nanometer; mm, millimeter; $\mathrm{NO}_{3}-\mathrm{N}$, nitrate-nitrogen; $\mathrm{mg} / \mathrm{L}$, milligrams per liter; \%, percent; ${ }^{\circ} \mathrm{C}$, degree Celsius; dia, diameter; $\mathrm{kg}$, kilogram; Max, maximum; m, meter; VAC, volts alternating current; VDC, volts direct current; amp, ampere; mA, milliamp]

\begin{tabular}{|c|c|c|c|}
\hline & HACH NITRATAX plus sc & Satlantic SUNA V2 & S::CAN Spectro::Iyser \\
\hline $\begin{array}{r}\text { Detection } \\
\text { protocol }\end{array}$ & $\begin{array}{l}\text { UV absorption at } \\
210 \mathrm{~nm} \& 350 \mathrm{~nm}\end{array}$ & $\begin{array}{l}\text { UV spectral analysis } \\
\quad(190-370 \mathrm{~nm})\end{array}$ & $\begin{array}{l}\text { UV-Visible Spectral analysis } \\
\quad(220-720 \mathrm{~nm})\end{array}$ \\
\hline Sample path length $(\mathrm{mm})$ tested & 5 and 2 & 5 & 5 \\
\hline $\begin{array}{l}\text { Software version of tested } \\
\text { analyzer }\end{array}$ & $\begin{array}{l}5 \mathrm{~mm} \text { - version } 3.06 \\
2 \mathrm{~mm} \text { - version } 3.13\end{array}$ & Version 2.5.0 & Information unavailable \\
\hline Lamp & Xenon & Deuterium & Xenon \\
\hline Detector & Patented 2 beam & Zeiss & Zeiss \\
\hline Optical configuration & Dual beam & Single beam & Split beam \\
\hline NO3-N range $(\mathrm{mg} / \mathrm{L})$ & $\begin{array}{l}5 \mathrm{~mm}-0.1-25 \\
2 \mathrm{~mm}-0.1-50\end{array}$ & $0.031-56$ & 0.005-70 (typical) \\
\hline Operating temperature range & $0 \pm 40^{\circ} \mathrm{C}$ & $0-35^{\circ} \mathrm{C}$ & $0-45^{\circ} \mathrm{C}$ \\
\hline Dimensions & $75 \mathrm{~mm}$ dia x $323 \mathrm{~mm}$ & $119 \mathrm{~mm}$ x $624 \mathrm{~mm}$ (with wiper) & $44 \mathrm{~mm}$ dia x $647 \mathrm{~mm}$ \\
\hline Weight (in air) & $3.6 \mathrm{~kg}$ & $3.1 \mathrm{~kg}$ & $2.1 \mathrm{~kg}$ \\
\hline Depth max & $100 \mathrm{~m}$ & $\begin{array}{l}500 \mathrm{~m} \\
100 \mathrm{~m} \text { (with wiper) }\end{array}$ & Not available \\
\hline Power & $120 \mathrm{VAC}$ or $24 \mathrm{VDC}$ & $12 \mathrm{VDC}$ & $12 \mathrm{VDC}$ \\
\hline Current draw (average) & Not available & $0.625 \mathrm{amp}$ & $20 \mathrm{~W} \max$ \\
\hline Communications & $\begin{array}{l}\text { Modbus/RS485, Modbus/RS232, } \\
\quad 4-20 \mathrm{~mA}\end{array}$ & $\begin{array}{l}\text { RS232, SDI-12, } \\
\text { 4-20 mA }\end{array}$ & $\begin{array}{l}\text { Modbus/RS232, Modbus/RS485, } \\
\text { 4-20 mA, SDI-12 }\end{array}$ \\
\hline
\end{tabular}




\section{Test Procedures}

The tests were conducted in two phases. Phase one testing, turbidity/SSC effect on accuracy, evaluated the effect of suspended sediment on the nitrate measurements made by the analyzers. Phase two testing, CDOM effect on accuracy, evaluated the effect of color on the nitrate measurements made by the sensors.

To create the testing environment for the analyzers, an open-top Chem-tainer10-gallon tank was purchased along with a stand (part number [pn] TC1528AP, The Tank Depot). The tank was designed with a cylindrical cone bottom, which was retrofitted with a drain tube and stopcock. Also purchased was an electric variable-speed 1/15th horsepower mixer (pn 34745K 71, McMaster-Carr), a stand with swivel connector (pn 35265K11, McMaster-Carr), a 4-inch stainless steel propeller (pn 8364T5, McMaster-Carr), a 12-inch stainless steel drive shaft (pn 8004K421, McMaster-Carr), and two pairs of mounting brackets (pn 1307T221, McMaster-Carr).

The measurement interval for all four sensors was set at once per minute. Measurements were made based upon the manufacturer's default calibrations and no offset values were applied. Signal averaging was initiated to obtain the numerical mean of three spectra or "counts" per reported value. The SUNA V2 was programmed to operate in continuous mode and the "deployed in salt water" option was disabled.

Sensor accuracy was verified prior to testing with a Hach-Lange 50-milligrams-per-liter (mg/L) $(11.3 \mathrm{mg}-\mathrm{N} / \mathrm{L})$ nitrate standard (lot number 13196). An acceptance range of plus or minus $( \pm) 10$ percent was established for the calibration verification. All sensors met the criteria: the Hach $(2 \mathrm{~mm})$ measured 11.5 milligrams nitrogen per liter (mg-N/L), the Hach $(5 \mathrm{~mm})$ measured $10.8 \mathrm{mg}-\mathrm{N} / \mathrm{L}$, the S:CAN measured $11.3 \mathrm{mg}-\mathrm{N} / \mathrm{L}$, and the SUNA V2 measured $10.8 \mathrm{mg}-\mathrm{N} / \mathrm{L}$.

\section{Turbidity/Total Suspended-Sediment Effect on Accuracy}

Phase I testing was originally conducted with only three sensors - two versions of the Hach NITRATAX plus sc (5 mm and $2 \mathrm{~mm}$ ) and the S::CAN Spectro::lyser. The test was later repeated and included the Satlantic SUNA V2. For the first round of testing, the tank was filled with 28 liters (L) of deionized water, and the mixer was set to produce a flow of approximately 1.5 feet per second. A 5-mg-N/L matrix spike was created by adding 140 milliliters $(\mathrm{mL})$ of a 1,000-mg/L nitrate standard (Ricca Chemical, pn 5307-16) to the $28 \mathrm{~L}$ of agitated deionized water (fig. 3).

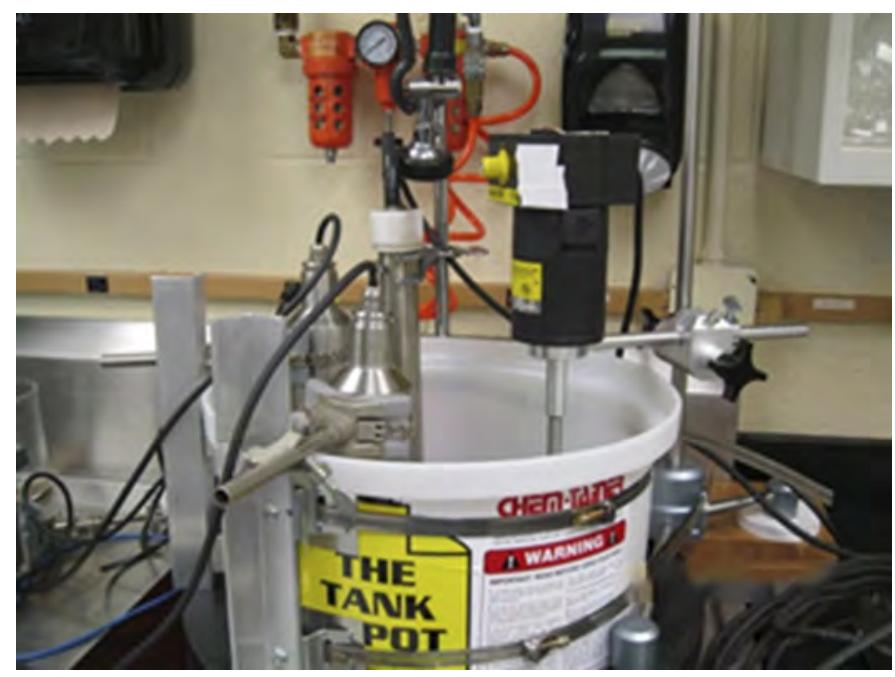

Figure 3. Photograph taken during the first round of suspended sediment testing showing the Hach NITRATAX (2-mm), Hach NITRATAX (5-mm), and the S:::CAN Spectro::Iyser (5-mm) nitrate sensors in the tank apparatus. 
The formula used to calculate the proper volumes for the matrix spike is shown below.

$$
X=\frac{(C n * V n)}{(C s)}
$$

where

$$
\begin{aligned}
\mathrm{X} & =\text { volume of nitrate stock standard to be diluted in milliliters }(\mathrm{mL}), \\
\mathrm{Cn} & =\text { concentration of the new standard in } \mathrm{mg} / \mathrm{L} \\
\mathrm{Vn} & =\text { total volume of the new standard in } \mathrm{mL}, \text { and } \\
\mathrm{Cs} & =\text { concentration of the standard to be diluted in } \mathrm{mg} / \mathrm{L}
\end{aligned}
$$

The uncertainty of the matrix spike was estimated at 1.22 percent at 95 -percent confidence and was calculated from the sum of the squares of the following variables (standard uncertainties) (Kirkup, 2006):

- 0.5 -percent error from the certified stock standard.

- Fourteen volumes of deionized water from a 2-L volumetric flask with a 0.025 -percent uncertainty (0.35-percent error).

Normal distribution was assumed for the variables.

When the Phase I test was repeated, the tank was filled with $32 \mathrm{~L}$ of deionized water to accommodate the optical path length in the SUNA V2, which is located higher in the body compared to the other sensors. The 5-mg-N/L matrix spike was created by adding $160 \mathrm{~mL}$ of the previously mentioned $1,000 \mathrm{mg} / \mathrm{L}$ nitrate standard to the $32 \mathrm{~L}$ of deionized water. The uncertainty of the matrix spike for this test was estimated at 1.28 percent at 95 -percent confidence and was derived from the previously mentioned variables with 16 volumes of deionized water from a 2-L volumetric flask with an uncertainty of 0.028 percent. The sensors were submerged in the spiked solution and allowed to acclimate for several minutes prior to starting the test (fig. 4). Initial measurements from the analyzers in the clear spiked solution were monitored to ensure they were working properly, and the turbidity of the clear solution was recorded as the baseline for the test.

The turbid solution was created by the addition of National Institute of Standards and Technology (NIST) Standard Reference Material 1646a-estuarine sediment. This grey-colored sediment was characterized and certified to be free of nitrogencontributing substances (fig. 5). Aliquots of this sediment were weighed gravimetrically on a Mettler AE200 digital balance and systematically added to the agitated spike solution in which the nitrate sensors were submerged.

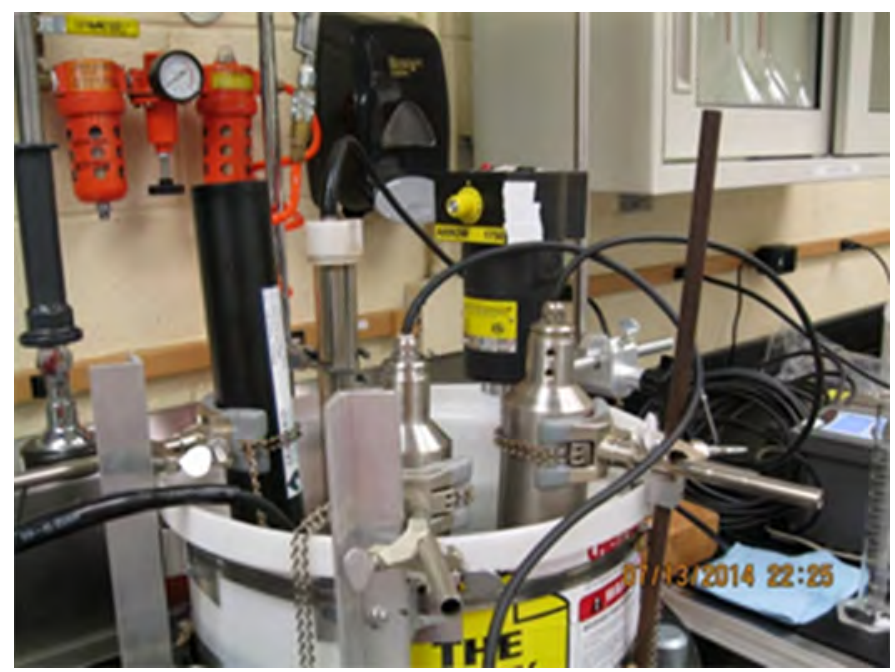

Figure 4. Photograph taken during the second round of suspended-sediment testing showing the Hach NITRATAX (2-mm), Hach NITRATAX (5-mm), S::CAN Spectro::lyser (5-mm), and the SUNA V2 (5-mm) nitrate sensors in the tank apparatus.

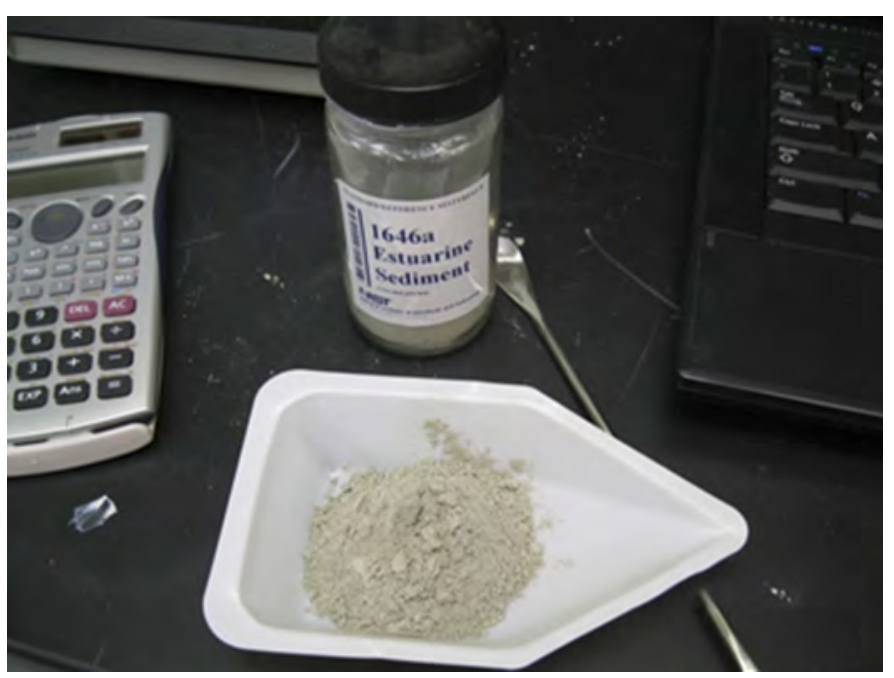

Figure 5. Photograph of the National Institute of Standards and Technology standard reference material 1646a-estuarine sediment. 
Nitrate and turbidity concentrations were recorded for SSC values that ranged from 10 to 2,000 $\mathrm{mg} / \mathrm{L}$ during the first round of testing, and from 10 to 4,500 mg/L during the second test. Turbidity was measured using a Hydrolab Datasonde 5x (Ds5X) equipped with a calibrated Hydrolab 5 series self-cleaning turbidity probe. The manufacturer specifications list the accuracy of the Hydrolab 5 series as \pm 1 percent ( $0.1-100$ formazin nephelometric units [FNU]), \pm 3 percent (101-400 FNU), and \pm 5 percent (401-3000 FNU) (Hach Hydromet Application Notes, [2014]).

\section{Colored Dissolved Organic Matter Effect on Accuracy}

The difficulty in the phase 2 testing (CDOM effect on accuracy) was in finding a suitable additive that would provide the brownish hue found in many surface waters and that would not interfere with the sensors at the wavelengths of interest. Food coloring was purchased and initially tried. A drop of food coloring was added to $1 \mathrm{~L}$ of deionized water and an aliquot was tested; every color produced a false-positive nitrate concentration of 5 to $10 \mathrm{mg}-\mathrm{N} / \mathrm{L}$ when analyzed on a calibrated UV-Vis benchtop spectrophotometer. Tea was also tested as a surrogate. A family-size tea bag of cold brew tea was added to $1 \mathrm{~L}$ of deionized water and allowed to diffuse for approximately 15 minutes (fig. 6). Initial tests on the benchtop spectrophotometer indicated a false nitrate concentration of $23 \mathrm{mg}-\mathrm{N} / \mathrm{L}$.

After the tea was filtered through a Pall 0.45-micron Versapor membrane filter, the nitrate concentration read less than detection when analyzed on the benchtop spectrophotometer. The filtered tea was selected as the CDOM source for the evaluation.

For the CDOM test, the tank was filled with $32 \mathrm{~L}$ of deionized water, and as with the suspended sediment test, spiked to a nitrate concentration of $5 \mathrm{mg}-\mathrm{N} / \mathrm{L}$, using the same spiking solution as in the phase 1 test. The four sensors were submerged in the tank and the mixer was adjusted to maintain a flow of approximately 1.5 feet per second. Measured aliquots of the filtered tea were added to the solution, and turbidity, ETOC, and nitrate concentrations were recorded to determine the effect of color on the measured nitrate concentrations. The S::CAN's ETOC values were not verified for accuracy prior to testing; therefore, these values were noted only as an increase in concentration from the baseline reading.

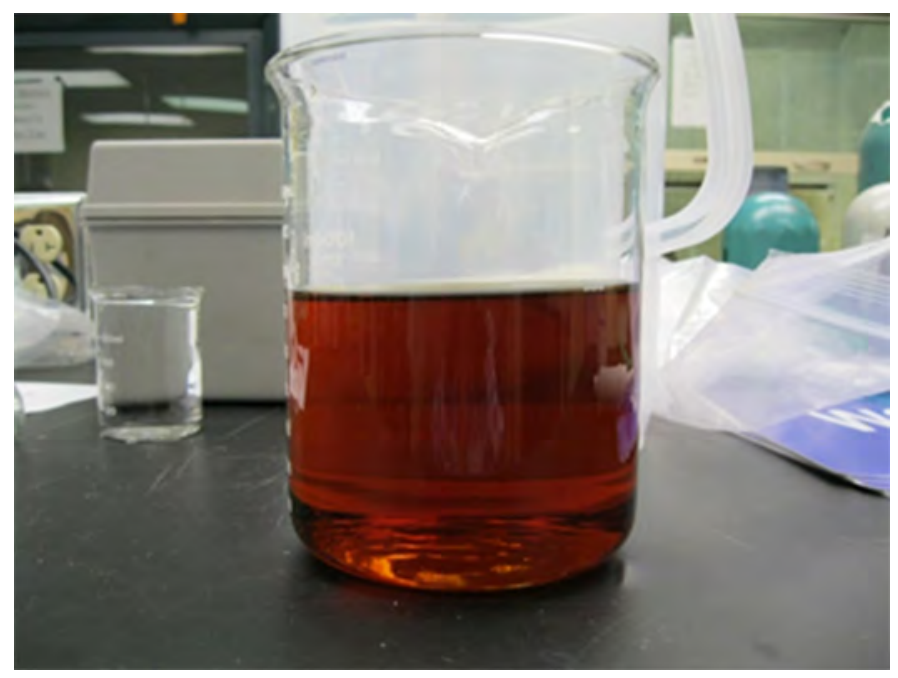

Figure 6. Photograph of the prefiltered brewed tea used in the test for colored dissolved organic matter.

\section{Test Results}

\section{Turbidity and Total Suspended-Sediment Effect on Accuracy}

SSC concentrations of $10 \mathrm{mg} / \mathrm{L}$ to $4,500 \mathrm{mg} / \mathrm{L}$ were added to the water bath and the effect on nitrate accuracy was recorded. Tables 2 and 3 summarize the results from the two tests, and figure 7 shows the difference between the initial nitrate measurements and subsequent nitrate measurements during the two tests as the SSC increased. 

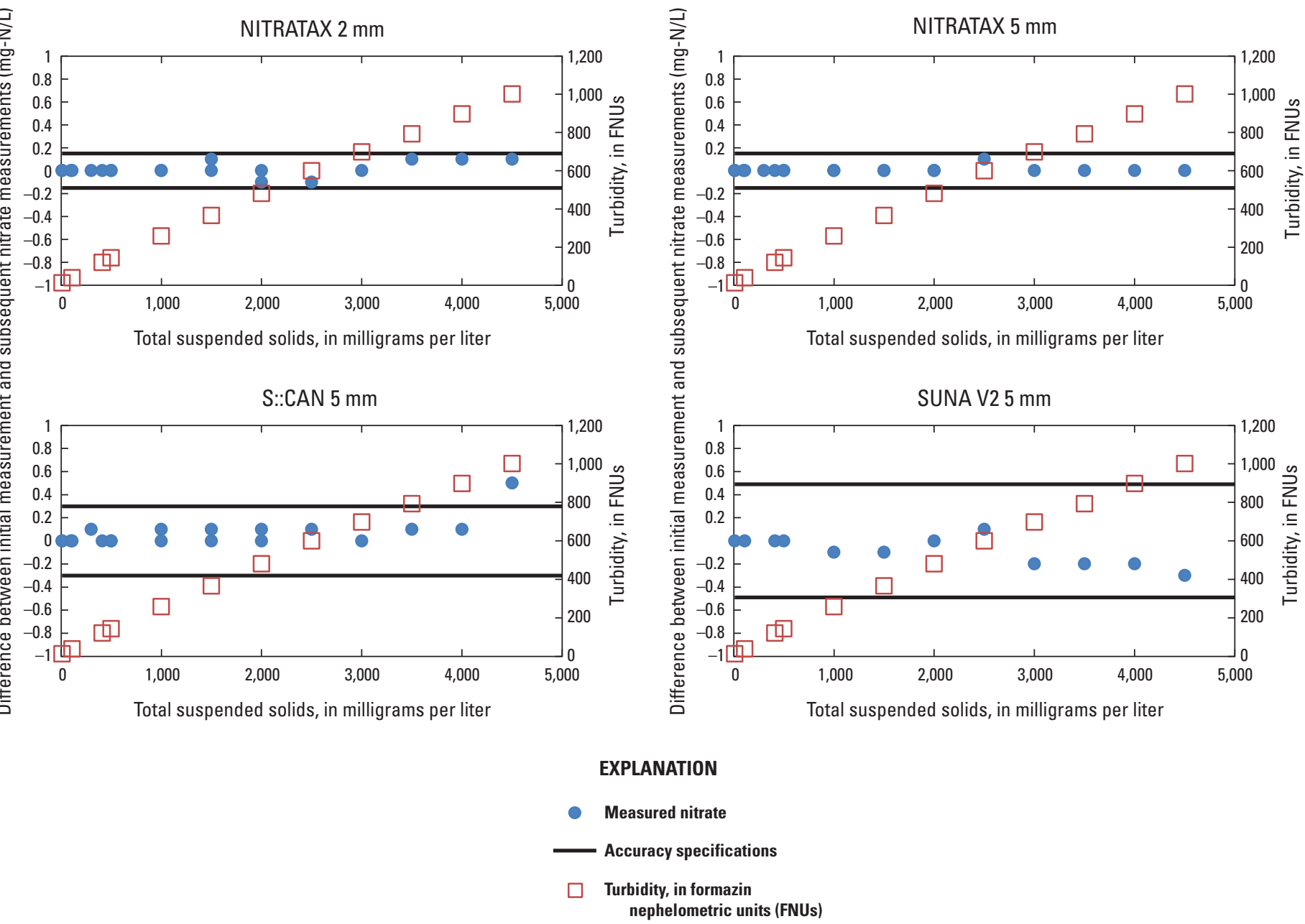

Figure 7. Difference between the initial nitrate measurement and subsequent nitrate measurements of the 5 milligrams-nitrogenper-liter (mg-N/L) solution by the Hach NITRATAX (2-mm), Hach NITRATAX (5-mm), S::CAN (5-mm), and SUNA V2 (5-mm) nitrate sensors in suspended-sediment concentration values from $0-4,500 \mathrm{mg} / \mathrm{L}$.

Little or no change was observed in any of the sensors' nitrate measurements during either of the phase 1 tests, although a noticeable change in water clarity was observed as the SSC was increased (fig. 8). Only at 4,500 mg/L SSC did the S::CAN's accuracy fail to meet the acceptance criteria $( \pm 0.31 \mathrm{mg}-\mathrm{N} / \mathrm{L})$, with a difference of $0.50 \mathrm{mg}-\mathrm{N} / \mathrm{L}$ between the initial and measured concentration. The SUNA V2 and both NITRATAX sensors $(2 \mathrm{~mm}$ and $5 \mathrm{~mm}$ ) consistently met their respective manufacturer specifications for accuracy.

\section{Colored Dissolved Organic Matter Effect on Accuracy}

Turbidity remained low during the color test and averaged only $5.5 \mathrm{FNU}$ as measured by the Hydrolab 5 series turbidity sensor. Estimated total organic carbon, as measured by the S::CAN Spectro::lyser, increased from $13.7 \mathrm{mg} / \mathrm{L}$ in deionized water to $44.6 \mathrm{mg} / \mathrm{L}$ at the completion of the test, and a noticeable change in water color was observed as the ETOC increased (fig. 9). Figure 10 shows the percent increase of measured nitrate concentration for each sensor compared to the increasing ETOC values. It is important to emphasize that the increase in nitrate concentration was not legitimate. The color additive, the filtered tea, was tested prior to the test for nitrate concentration using a calibrated benchtop spectrophotometer, and nitrate concentration registered at less than detection. All four sensors were adversely affected to varying degrees. The SUNA V2 performed the best in the evaluation. The SUNA's measured nitrate stayed within 5 percent of the true value in ETOC concentrations up to $20 \mathrm{mg} / \mathrm{L}$. The SUNA's data showed a 24-percent error for the maximum ETOC concentration. The NITRATAX 5-mm path length had the next best performance with measured nitrate remaining within 5 percent of the true value in ETOC concentrations up to $17 \mathrm{mg} / \mathrm{L}$. NITRATAX data resulted in a 49-percent error at the maximum ETOC concentration recorded during the test. 
The Effect of Suspended Sediment and Color on Ultraviolet Spectrophotometric Nitrate Sensors
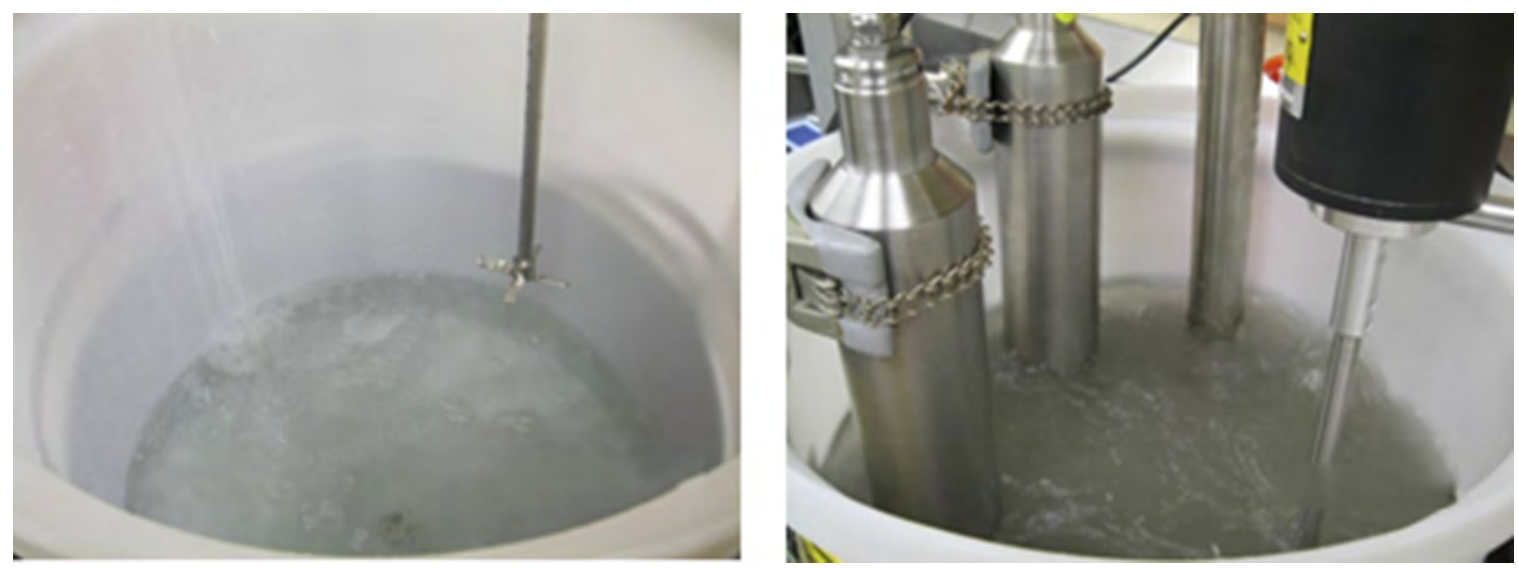

Figure 8. Photographs showing the initial clear matrix spike of the turbidity/total suspended sediment (tss) test (left) and the ending matrix spike of the turbidity/tss test containing the addition of 4,500 milligrams per liter of National Institute of Standards and Technology standard reference material 1646a-estuarine sediment (right).

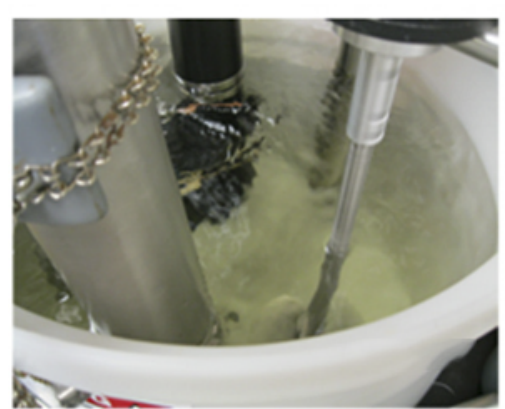

$17.5 \mathrm{mg} / \mathrm{L}$

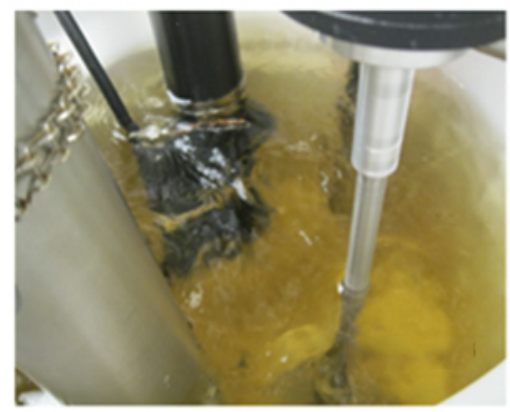

$27.5 \mathrm{mg} / \mathrm{L}$

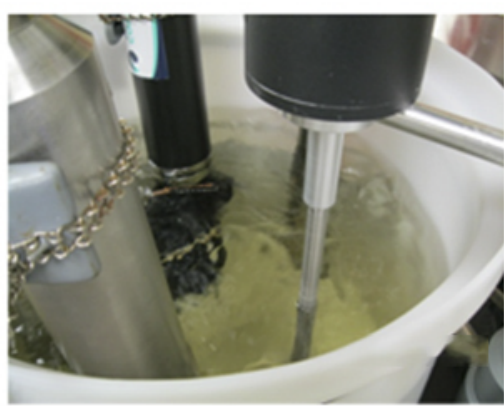

$19.1 \mathrm{mg} / \mathrm{L}$

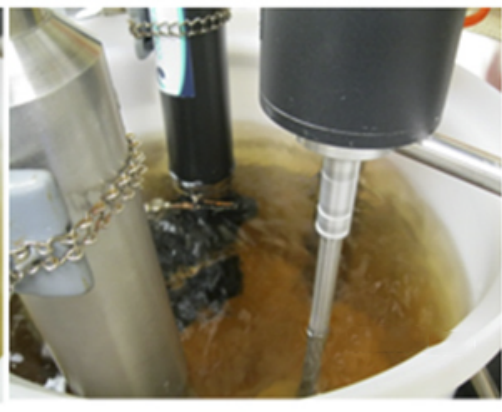

$35.5 \mathrm{mg} / \mathrm{L}$

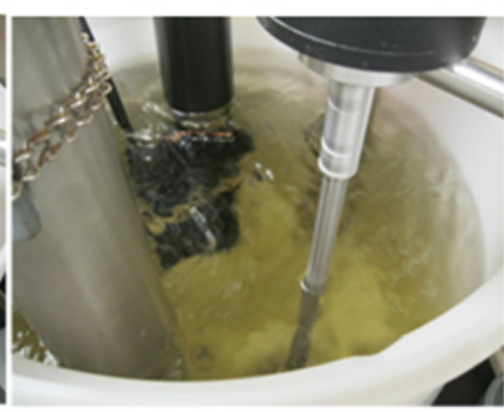

$21.6 \mathrm{mg} / \mathrm{L}$

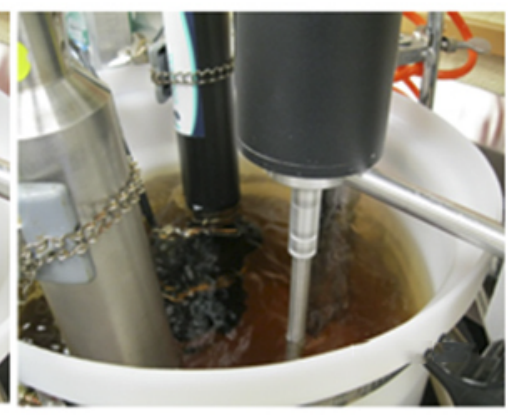

$44.6 \mathrm{mg} / \mathrm{L}$

Figure 9. Photographs showing the observed color change as the estimated total organic carbon (ETOC) increases (left to right, top to bottom). Measured aliquots (in milligrams per liter, $\mathrm{mg} / \mathrm{L}$ ) of filtered "nitrate-free" tea were added to increase the ETOC values. 

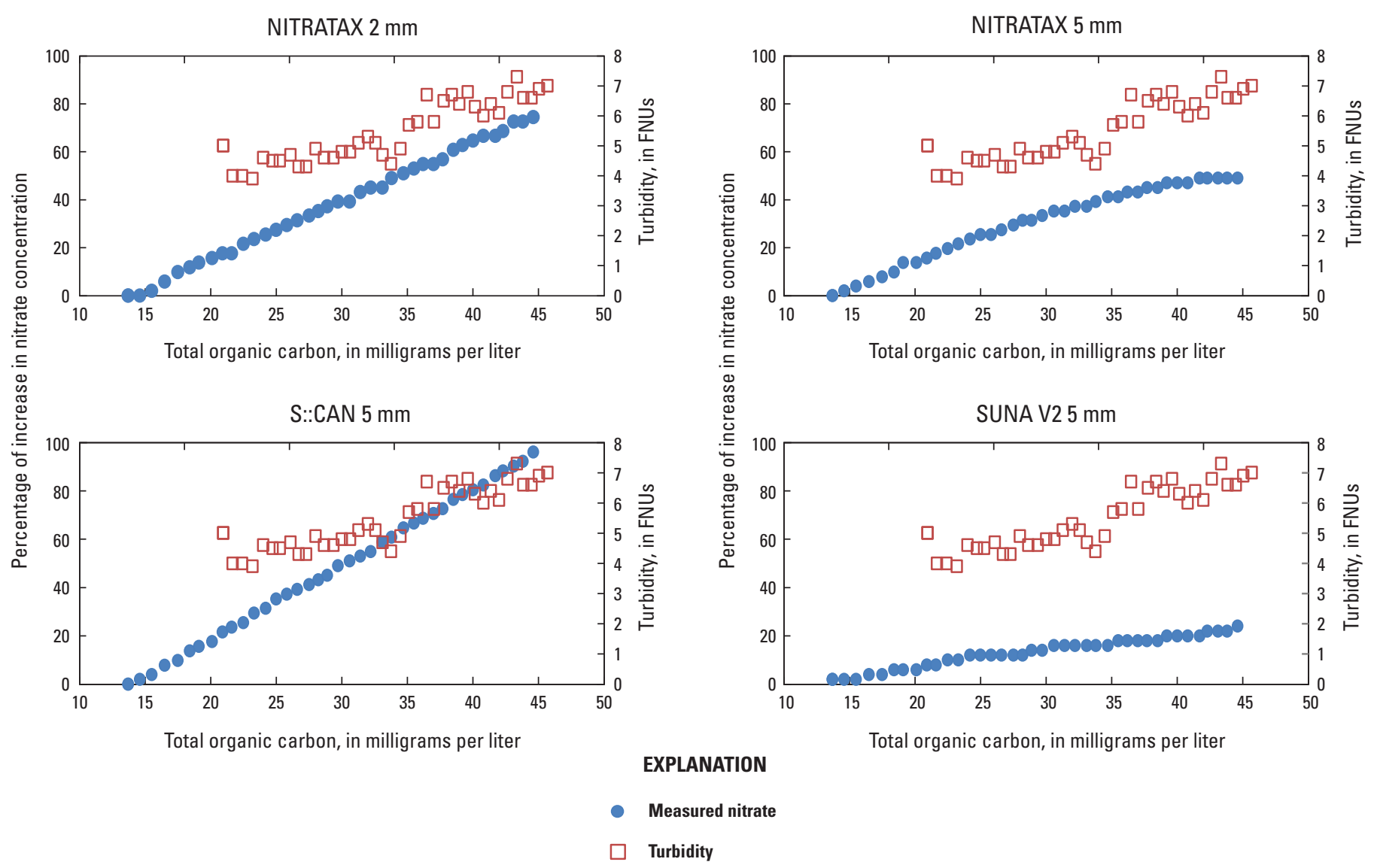

Figure 10. Percent $(\%)$ increase in measured nitrate concentration by the Hach NITRATAX (2-mm), Hach NITRATAX $(5-\mathrm{mm})$, S::CAN $(5-\mathrm{mm})$, and SUNA V2 $(5-\mathrm{mm})$ nitrate sensors against increasing estimated total organic carbon. Turbidity is plotted as the red squares in formazin nephelometric units (FNUs).

Data from the NITRATAX 2-mm remained within 5 percent of the true value in ETOC concentrations up to $17 \mathrm{mg} / \mathrm{L}$, and showed a 75-percent error at the maximum ETOC concentration. The S::CAN's measured values remained within 5 percent of the true value in ETOC concentrations less than $15 \mathrm{mgL}$, and showed a 96-percent error at the maximum ETOC concentration. Theoretically, the NITRATAX $2 \mathrm{~mm}$ should have performed better than the NITRATAX $5 \mathrm{~mm}$ due to the shorter path length, and initial test results verified this theory. The nitrate concentration reported by the $2-\mathrm{mm}$ sensor was relatively unaffected up to an ETOC concentration of $15.5 \mathrm{mg} / \mathrm{L}$, while the concentration reported by the 5-mm sensor was adversely affected at an ETOC concentration of $14.6 \mathrm{mg} / \mathrm{L}$. At an ETOC concentration of $16.5 \mathrm{mg} / \mathrm{L}$, both the $2-\mathrm{mm}$ and the $5-\mathrm{mm}$ sensors showed an approximate 6-percent increase in nitrate concentration. This result suggests that path length alone does not determine a sensor's ability to compensate for all interferences. Table 4 summarizes the volumes of tea solution added and the resulting increases in ETOC and "false" nitrate concentration for each tested nitrate sensor.

\section{Summary}

The recent availability of commercial ultraviolet (UV) spectrophotometers provides the opportunity to monitor nitrate concentration in situ, and thereby increases the potential frequency of sample analysis by eliminating the logistical constraints of discrete-only water sampling. However, interferences like suspended sediment and colored dissolved organic matter (CDOM) present major challenges to the sensor abilities. In this report, four of the most popular models of UV nitrate sensors were tested to determine what effect suspended-sediment concentration (SSC), from a certified nitrate-free sediment standard and CDOM produced from filtered tea, would have on sensor accuracy.

In this evaluation, there was little effect on the sensors' accuracy from the National Institute of Standards and Technology standard-reference-material-induced SSC. Accuracy specifications were met by the Hach NITRATAX (5 mm), Hach NITRATAX $(2 \mathrm{~mm})$, and the Satlantic SUNA V2 $(5 \mathrm{~mm})$ in the SSC test with concentrations from 10 to $4,500 \mathrm{mg} / \mathrm{L}$. The accuracy specifications were not met in the phase I test by the S::CAN Spectro::lyser $(5 \mathrm{~mm})$ for SSC values above 4,000 $\mathrm{mg} / \mathrm{L}$. The effect of CDOM significantly affected measurement accuracy of all four sensors, with errors ranging from 20 to 96 percent 
of measurement values for the maximum-tested ETOC concentration of $45 \mathrm{mg} / \mathrm{L}$. The SUNA V2 performed the best in the CDOM test with a 24-percent false increase in measured nitrate concentration at an ETOC concentration of $45 \mathrm{mg} / \mathrm{L}$. Nitrate concentration was falsely elevated at the maximum ETOC concentration by 49 percent for the NITRATAX 5-mm sensor, and 75 percent for the NITRATAX 2-mm sensor. The S::CAN's measured nitrate concentration artificially doubled from $5 \mathrm{mg}-\mathrm{N} / \mathrm{L}$ to 10 $\mathrm{mg}-\mathrm{N} / \mathrm{L}$ by the end of the test (that is, at the $45-\mathrm{mg} / \mathrm{L}$ ETOC concentration). Results of this evaluation indicate that although suspended sediment and CDOM interfere with all of the UV spectrophotometric nitrate sensors, the sensors are more effective compensating for suspended sediment and less effective compensating for CDOM. These results suggest that the end user of these sensors should be aware of the potential skewing of the data due to these interferences, especially if the site is one that has highly colored (chromophoric) water.

\section{Acknowledgments}

The author thanks Jacob Gibs (retired) of the U.S. Geological Survey (USGS) New Jersey Water Science Center; Paul Terrio of the USGS Illinois Water Science Center; and Janice Fulford of the USGS Hydrologic Instrumentation Facility (HIF) for providing valuable technical information throughout the study. Finally, many thanks go to the staff of the HIF Water Quality Servicing Laboratory for their help and support in this project.

\section{References Cited}

American Public Health Association, 1989, Standard methods for the examination of water and wastewater, 17th ed.: Washington, D.C., American Public Health Association.

Blough, N.V., and Del Vecchio, R., 2002, Chromophoric DOM in the coastal environment, in Hansel, D.A., and Carlson, C.A., eds., Biogeochemistry of marine dissolved organic matter: San Diego, Calif., Academic Press, p. 509-546.

Danaher Business System [2012a], Hach products and ordering: Hach Company Web page, accessed September 3, 2012, at http://www.hach.com.

Danaher Business System [2012b], SUNA V2 UV nitrate sensor: Satlantic Web page, accessed September 3, 2012, at http:// www.satlantic.com/suna.

Danaher Business System [2012], Web page, accessed September 3, 2012, at http://www.satlantic.com/suna.

Hach NITRATAX sc user manual (6th ed.), 2014, Hach, accessed July 1, 2015, at http://www.hach.com/nitratax-plus-sc-sensor2-mm-path-length/product-downloads?id=7640095062.

Hach Hydromet Application Notes, 2014, Hydrolab Series 5 Turbidity Sensor: OTT Hydromet, accessed March 24, 2014, at http://www.ott.com/en-us/products/sensor/turbidity-sensor/.

Johnson K.S., and Coletti, L.J., 2002, In situ ultraviolet spectrophotometry for high resolution and long-term monitoring of nitrate, bromide and bisulfide in the ocean in Deep-Sea Research Part I; Oceanographic Research Papers: Elsevier, v. 49, p. 1291-1305.

Kirkup, L.B., 2006, An introduction to uncertainty in measurement using the GUM (guide to the expression of uncertainty in measurement): Cambridge, Mass., Cambridge University Press.

Pellerin, B.A., Bergamaschi, B.A., Downing, B.D., Saraceno, J.F., Garrett, J.D., and Olsen, L.D., 2013, Optical techniques for the determination of nitrate in environmental waters; Guidelines for instrument selection, operation, deployment, maintenance, quality assurance, and data reporting: U.S. Geological Survey Techniques and Methods 1-D5, 37 p., accessed July 1, 2015, at http://pubs.usgs.gov/tm/01/d5/.

S::can messtechnik GmbH, S::can home page [2012]: S::can messtechnik GmbH Web page, accessed September 2, 2012, at http://www.s-can.us/.

Snazelle, T.T., 2015, Results from laboratory and field testing of nitrate measuring spectrophotometers: U.S. Geological Survey Open-File Report 2015-1065, 35 p., accessed July 1, 2015, at http://dx.doi.org/10.3133/ofr20151065.

Satlantic LP, 2014, SUNA Manual Rev. E: Halifax, Nova Scotia, Satlantic LP, accessed July 1, 2015, at http://satlantic.com/sites/ default/files/documents/Satlantic-SUNA-V2-Manual-Rev-E.pdf. 
For additonal information, visit http://water.usgs.gov/hif/ USGS Publishing Service Center staff:

Marilyn A. Billone, Editor

James E. Banton, layout 


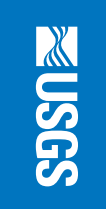

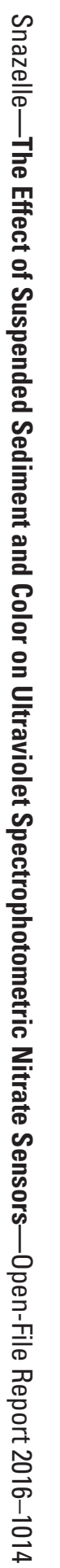

